\title{
Global systematics of arc volcano position
}

\author{
Philip C. England ${ }^{1}$ \& Richard F. Katz ${ }^{1}$ \\ ${ }^{1}$ Department of Earth Sciences, Parks Road, Oxford OX1 3PR. UK.
}

This is an author-prepared copy of the final version of this paper. The published version is in Nature, v468, 700-704, doi:10.1038/nature09154

http://www.nature.com/nature/journal/v468/n7325/full/nature09154.html

Global systematics in the location of volcanic arcs above subduction zones ${ }^{1,2}$ are widely considered to be a clue to the melting processes that occur at depth, and the locations of the arcs have often been explained in terms of the release of hydrous fluids near the top of the subducting slab (e.g. ${ }^{3-6}$ ). Grove $e t$ $a l .{ }^{7}$ hypothesize that arc location is controlled by melting in the mantle at temperatures above the watersaturated upper-mantle solidus and below the upper limit of stability of the mineral chlorite (conditions defined as $P, T_{\text {melt }}$ in their Fig $1 \mathrm{~b}$ ). Specifically, they argue that arc volcanism occurs directly above the shallowest point of the region in which mantle conditions satisfy the $P, T_{\text {melt }}$ criterion. Grove et al. ${ }^{7}$ then use numerical models of subduction zones to predict arc location and its global systematics. They conclude that agreement between their calculated systematics of arc location and observations of real subduction zones $^{2,8}$ validates their hypothesis (Grove et al. ${ }^{7}$, Figure 3 ). We show that this conclusion is undermined by two flaws: first, Grove et al.'s ${ }^{7}$ calculated arc locations are in error due to inadequate spatial resolution of their numerical models; second, the agreement that they find between predicted and observed systematics arises from a spurious correlation of calculated arc location with slab dip.

Before we address these two points in detail, however, a problem with the results presented by Grove et al. $^{7}$ is evident. A characteristic feature of subduction-zone models ${ }^{9}$ is the narrow thermal boundary layer, sub-parallel to and just above the slab surface, which contains the temperature range of $P, T_{\text {melt }}(\sim 800-$ $850^{\circ} \mathrm{C}$ ). For all but the slowest convergence rates, this boundary layer begins close to the depth at which the slab is viscously coupled to the wedge. Hence one should expect the region enclosing $P, T_{m e l t}$ to be a very thin, continuous layer above the slab, with its shallowest extent at an essentially constant depth. The results of Grove et al. ${ }^{7}$ (green points in Fig. 2) are inconsistent with this expectation, and raise the suspicion of an error in their calculation.

To locate their region of $P, T_{\text {melt }}$, Grove et al. ${ }^{7}$ determined which nodes of their $2.3 \times 2.3-\mathrm{km}$ computational mesh lay within that $P-T$ range. Because those conditions occur within a boundary layer only a few kilometres thick that is inclined at an angle to the mesh, this procedure did not resolve the full extent of the $P, T_{\text {melt }}$ region. To check their results, we calculated the temperature fields for subduction zones on a $1 \times 1-\mathrm{km}$ grid, then resampled it to both $2.3 \mathrm{~km}$ and to $0.25 \mathrm{~km}$ resolution. This was done for a range of subduction parameters and for each calculation we determined the $P, T_{\text {melt }}$ region and its shallowest point. We found that at 2.3-km resolution, the minimum depth of $P, T_{\text {melt }}$ ranged between about 57 and $76 \mathrm{~km}$, consistent with the range found by Grove et al. ${ }^{7}$. On the $0.25 \mathrm{~km}$ grid, however, the minimum depth was confined between 57 and $61 \mathrm{~km}$ (Figure 1a), consistent with expectations laid out in the preceding paragraph. At either resolution, the minimum depth of $P, T_{\text {melt }}$ is independent of the slab dip and of the convergence rate.

Grove et al. ${ }^{7}$ compare their calculations with seismic studies, which show that the depth-to-slab beneath arcs varies between $\sim 80$ and $\sim 150$ kilometres $^{2,8}$ and has a negative correlation with the descent speed of the slab (Figure 1b). The depth to the top of the slab predicted by Grove et al.'s ${ }^{7}$ hypothesis applied under our recalculations is $\sim 60-75 \mathrm{~km}$, independent of dip or convergence rate (Figure 1b), and thus is in disagreement with the observations. 
The agreement between model and observations in Grove et al. ${ }^{7}$ is spurious, and is the result of their choice of variables. Figure 1c recreates their Figure 3, which shows the apparent consistency between model and observations, using our recalculated location of arcs. The sine of slab dip is plotted on the $x$-axis, and on the $y$-axis is the distance to the trench, which for all points (calculated and observed - Grove et al. ${ }^{7}$, Table 1) is taken as the depth-to-slab divided by the tangent of the dip. The presence of the sine of the dip on each axis ensures a spurious correlation; this is illustrated clearly in Figure 1c by the grey line that corresponds to a constant value of $D_{\text {Slab }}=62 \mathrm{~km}$.

Thus there is no significance in the match between models and observations reported by Grove et $a l .{ }^{7}$, and their conclusion that "the kinematic control on the location of mantle melting is primarily slab dip" (Grove et $_{\text {al. }}{ }^{7}$, p. 696) is mistaken. A more informative conclusion to draw from their experiments is that the limits of chlorite stability (Grove et al. Figure 1b) ${ }^{7}$ cannot explain the global systematics in the depth to the slab beneath the sharply localized arc fronts. Indeed, this remark applies to any strongly temperaturedependent processes that takes place near the top of the slab, for the reasons laid out in this comment.

1. Tovish, A. \& Schubert, G. Island arc curvature, velocity of convergence and angle of subduction. Geophys. Res. Letts. 5, 329-332 (1978).

2. England, P., Engdahl, R. \& Thatcher, W. Systematic variation in the depths of slabs beneath arc volcanoes. Geophys. J. Int. 156, 377-408 (2004).

3. Gill, J. Orogenic Andesites and Plate Tectonics (Springer-Verlag, New York, 1981).

4. Tatsumi, Y. \& Eggins, S. Subduction Zone Magmatism (Blackwell Science, Cambridge, MA, 1995).

5. Iwamori, H. Transportation of $\mathrm{H}_{2} \mathrm{O}$ and melting in subduction zones. Earth Plan. Sci. Lett. 160, 65-80 (1998).

6. Tatsumi, Y. The subduction factory: How it operates in the evolving Earth. GSA Today 15, 4-10 (2005).

7. Grove, T., Till, C., Lev, E., Chatterjee, N. \& Médard, E. Kinematic variables and water transport control the formation and location of arc volcanoes. Nature 459, 694-697 (2009).

8. Syracuse, E. \& Abers, G. Global compilation of variations in slab depth beneath arc volcanoes and implications. Geochem. Geophys. Geosys. 7, 18.

9. van Keken, P. et al. A community benchmark for subduction zone modeling. Phys. Earth Planet. In. 171, 187-197 (2008). 

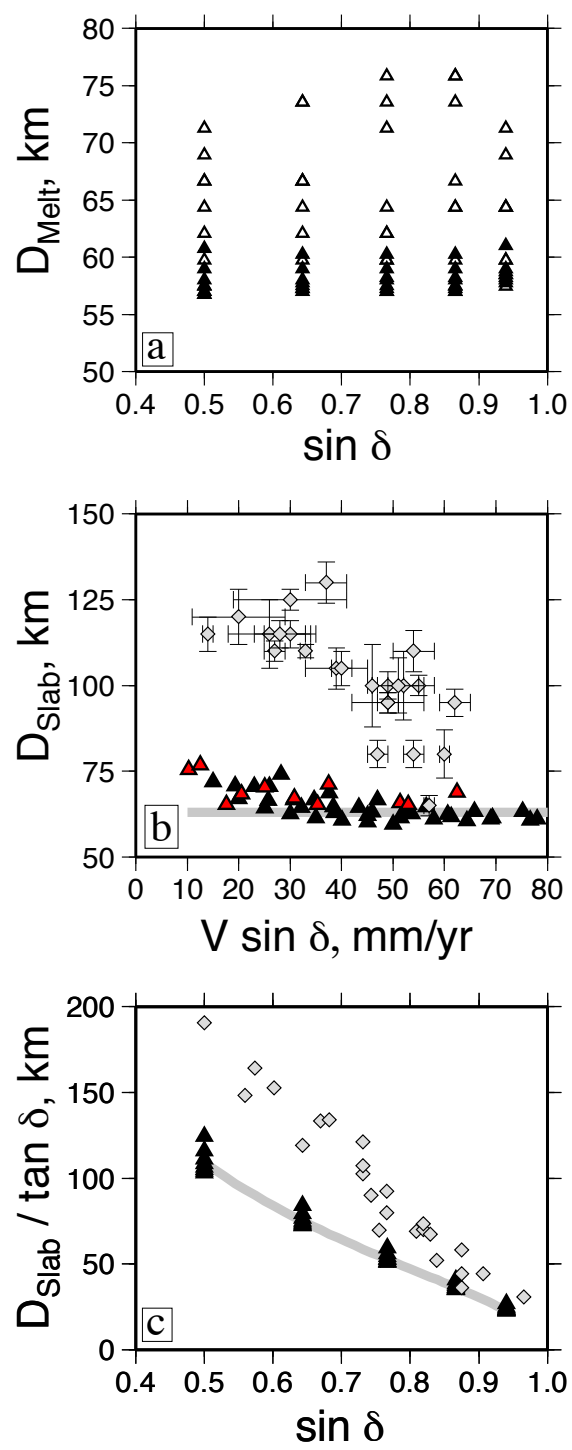

Figure 1: (a) Calculated depth $D_{\text {Melt }}$ of the shallowest portion of the $P, T_{m e l t}$-based melting field (c.f. Figs. 1 and 2 of Grove et $\mathrm{l}^{7}{ }^{7}$ ). Calculations were carried out on a 1-km finite-volume $\mathrm{mesh}^{9}$, for dip $\delta$ of $30^{\circ}$ to $70^{\circ}$ in steps of $10^{\circ}$, and for convergence rate $V$ from 30 to $100 \mathrm{~mm} / \mathrm{yr}$, in steps of $10 \mathrm{~mm} / \mathrm{yr}$; these ranges include the parameters of the calculations of Grove $e t a l{ }^{7}$. The points correspond to the minimum depths of melting calculated according to the hypothesis and methods of Grove et al. ${ }^{7}$ for $2.3 \times 2.3 \mathrm{~km}$ resampled grid (open triangles) and for a $0.25 \times 0.25 \mathrm{~km}$ resampled grid (filled triangles). (b) Diamonds show depth-to-slab determined seismologically ${ }^{2}$; filled triangles show the calculated depth of the slab $D_{\text {Slab }}$ below the locus of shallowest melting, for the $0.25 \mathrm{~km}$ resampled grid from panel (a). The red triangles correspond to the corrected upper limits of the $P, T_{\text {melt }}$ region for the combinations of dip and convergence rate used by Grove et al. ${ }^{7}$ (T. Grove et al., pers. comm). The grey line corresponds to a constant $D_{\text {Slab }}=62 \mathrm{~km}$. (c) Points as for panel (b), plotted on an ordinate that is the horizontal distance between the trench and the $\operatorname{arc}$ (which is equal to $D_{\text {Slab }} / \tan \delta$ ). The grey line corresponds to $D_{\text {Slab }}=62 \mathrm{~km}$ and demonstrates the spurious correlation referred to in the text. This panel corresponds to the lower $200 \mathrm{~km}$ of Grove et $^{\text {al. }}{ }^{7}$, Figure 3. 